\title{
Praseodymium iridium oxide as a competitive electrocatalyst for oxygen evolution reaction in acid media
}

\author{
Yimeng Wang ${ }^{\dagger}$, Shangguo Liu ${ }^{\dagger}$, Qing Qin*, Huihui Liu, Lijie Zhang, Tao Wei, Haisen Li and \\ Xien Liu
}

\begin{abstract}
Amorphous iridium oxides $\left(\operatorname{IrO}_{x}\right)$ are highly active for oxygen evolution reaction (OER) in acid media; however, it is generally unstable compared with commercial $\mathrm{IrO}_{2}$. Recently, many non-noble metal-iridium mixed oxides are prepared for catalyzing OER efficiently. Herein, we report a cubic fluorite-type praseodymium iridium oxide with the surface of $\operatorname{IrO}_{x}\left(\mathrm{IrO}_{x} / \mathrm{Pr}_{3} \mathrm{IrO}_{7}\right)$ that shows the improved activity and stability in $0.1 \mathrm{~mol} \mathrm{~L}^{-1} \mathrm{HClO}_{4}$ solution, characterized by an overpotential of $305 \mathrm{mV}$ at the benchmark of $10 \mathrm{~mA} \mathrm{~cm}{ }^{-2}$ and a small Tafel slope of $37 \mathrm{mV} \mathrm{dec}^{-1}$, indicating a fast reaction kinetics and a competitive activity compared with the benchmark $\mathrm{IrO}_{2}$ and most reported electrocatalysts. The initial potential increases by less than $0.07 \mathrm{~V}$ after continuous OER testing over $60,000 \mathrm{~s}$. In contrast, $\mathrm{IrO}_{2}$ becomes nearly inactive for the OER within 20,000 s. Density functional theory calculations uncover that the optimal energy level path follows lattice oxygen mechanism (LOM). This work enlarges the family of the $\mathrm{IrO}_{x}$-type OER electrocatalyst in acid media.
\end{abstract}

Keywords: oxygen evolution reaction, water splitting, electrocatalysts, non-noble metal, energy conversion

\section{INTRODUCTION}

Proton exchange membrane (PEM) water electrolysis is regarded as an important clean energy technology in the sustainable energy landscape to produce hydrogen [1-6]. Despite intense research, serious challenges remain because of the lack of low-cost, high-efficiency anodic electrocatalysts for boosting the sluggish oxygen evolution reaction (OER) $[7,8]$. Currently, iridium oxides are considered the most promising candidates to tackle the aforementioned challenges, especially the recently reported non-noble metal-iridium mixed oxides, such as Ir$\mathrm{Ni}$ oxides [9-11], $\mathrm{SrIrO}_{3}$ perovskite [12], $\mathrm{Ba}_{2} \mathrm{PrIrO}_{6}$ and $\mathrm{Ba}_{2} \mathrm{YIrO}_{6}$ double perovskites [13], and $\mathrm{Pb}_{2} \mathrm{Ir}_{2} \mathrm{O}_{6.5}$ and $\mathrm{Y}_{2} \mathrm{Ir}_{2} \mathrm{O}_{7}$ pyrochlores [14,15], which not only significantly enhance the OER activities, but also reduce the costs, when compared with the state-of-the-art, commercially available $\mathrm{IrO}_{2}$. Many $\mathrm{IrO}_{x}$-type OER catalysts are formed by surface restructuring upon electrochemical leaching of non-noble metal ion under harsh conditions [16-19].

Besides the activity, the stability of an electrocatalyst is also very important. Experimental results combined with density functional theory (DFT) calculations indicate that dynamic surface reconstruction and formation of amorphous iridium oxide structure contribute greatly to high OER activities of the above mentioned electrocatalysts $[12,15]$, but the reconstruction also causes the decrease of the stability. Therefore, more stable $\mathrm{IrO}_{x}$-type OER catalysts need to be designed and prepared as a fundamental prerequisite to harness the superior catalytic activity of amorphous iridium oxides.

In this work, we demonstrate a competitive electrocatalytic OER activity and stability in acidic medium after $\mathrm{Pr}$ ion leaching of a fluorite-type praseodymium iridium oxide $\left(\mathrm{Pr}_{3} \mathrm{IrO}_{7}\right)$, which is comparable to the commercial $\mathrm{IrO}_{2}$ and most reported Ir-based OER electrocatalysts. Especially, the mass activity is approximately 4.8 times higher than that of $\mathrm{IrO}_{2}$ at $1.58 \mathrm{~V}$ ( $v s$. reversible hydrogen electrode (RHE)). Surprisingly, the resulting $\mathrm{IrO}_{x} / \mathrm{Pr}_{3} \mathrm{IrO}_{7}$ shows the enhanced stability for the OER compared with $\mathrm{IrO}_{2}$ using glass carbon as the working electrode. DFT calculations reveal that the surface Ir $5 \mathrm{~d}$ orbitals of $\mathrm{IrO}_{x} /$

College of Chemical Engineering, College of Chemistry and Molecular Engineering, Qingdao University of Science and Technology, Qingdao 266042, China

${ }^{\dagger}$ These authors contributed equally to this work.

* Corresponding authors (emails: qinqing@qust.edu.cn (Qin Q); liuxien@qust.edu.cn (Liu X)) 
$\mathrm{Pr}_{3} \mathrm{IrO}_{7}$ are at a lower energy level than the $\mathrm{O} 2 \mathrm{p}$ orbitals, which will reduce the charges on oxygen atom, thus making it escape easily from the lattice to participate the OER process.

\section{EXPERIMENTAL SECTION}

\section{Chemicals}

$\mathrm{C}_{6} \mathrm{H}_{9} \mathrm{O}_{6} \mathrm{Pr} \cdot x \mathrm{H}_{2} \mathrm{O}(\mathrm{M}: 318.03,99.9 \%)$, and $\mathrm{IrCl}_{4} \cdot x \mathrm{H}_{2} \mathrm{O}(\mathrm{M}$ : 334.03 , Ir 48.0\%-55.0\%) were purchased from Aladdin. The commercial $\mathrm{IrO}_{2}$ (99.9\%) was purchased from Macklin. Other reagents were purchased and directly used without purification.

\section{Synthesis of $\mathrm{Pr}_{3} \mathrm{IrO}_{7}$ catalyst}

In a typical procedure, $33.4 \mathrm{mg}$ of $\mathrm{IrCl}_{4} \cdot x \mathrm{H}_{2} \mathrm{O}$ was firstly mixed with $63.6 \mathrm{mg}$ of $\mathrm{C}_{6} \mathrm{H}_{9} \mathrm{O}_{6} \mathrm{Pr} \cdot x \mathrm{H}_{2} \mathrm{O}$ by fully grinding in an agate mortar. Then, the solid powder was put into a tube furnace using corundum crucible as utensil. After annealing at $1200^{\circ} \mathrm{C}$ for $4 \mathrm{~h}$ under ambient conditions, the obtained products were collected for electrochemical testing. To investigate the influence of reaction temperature on the catalytic performance, a series of temperature-dependent experiments were carried out.

\section{Electrochemical measurements}

The electrocatalytic OER performance of the prepared catalysts was investigated in a typical three-electrode system, in which carbon rod and the RHE were used as the counter electrode and reference electrode, respectively. The glass carbon (GC, $3 \mathrm{~mm}$ in diameter) with loading of $0.2 \mathrm{mg}$ of catalyst was served as the working electrode. The electrolyte was $0.1 \mathrm{~mol} \mathrm{~L}^{-1} \mathrm{HClO}_{4}$ solution. The polarization curves were measured in the potential range of $1.0-1.65 \mathrm{~V}$ ( $v s$. RHE), with a scanning speed of $5 \mathrm{mV} \mathrm{s}^{-1}$. All data were obtained with $i R$ (95\%) compensation. The electrochemical impedance spectroscopy (EIS) measurements were carried out at an open circuit potential within the frequency range of $100 \mathrm{kHz}-0.01 \mathrm{~Hz}$. The durability testing was conducted by a chronopotentiometry method at $10 \mathrm{~mA} \mathrm{~cm}^{-2}$.

\section{RESULTS AND DISCUSSION}

The synthesis of $\mathrm{Pr}_{3} \mathrm{IrO}_{7}$ pre-catalyst was conducted via a simple one-step solid-state reaction under air atmosphere. As shown in Fig. 1a, all the X-ray diffraction (XRD) peaks of pre-catalyst match well with orthorhombic $\mathrm{Pr}_{3} \mathrm{IrO}_{7}$ with unit cell parameters of $a=$ $10.9782 \AA, b=7.4389 \AA, c=7.5361 \AA$ (PDF No. 97-0099670 ), which is one superstructure of typical cubic fluorite-type iridates $\mathrm{Ln}_{3} \mathrm{IrO}_{7}(\mathrm{Ln}=\mathrm{Pr}, \mathrm{Nd}, \mathrm{Sm}, \mathrm{Eu})$ with the space group $\mathrm{Cmcm}$ [20]. The corresponding crystal structure is shown in Fig. S1, featured with chains of tilted and vertex-sharing $\mathrm{IrO}_{6}\left(\mathrm{Ir}^{5+}\right)$ octahedra oriented along the $c$-axis [21]. The representative scanning electron microscopy (SEM) image of the prepared $\mathrm{Pr}_{3} \mathrm{IrO}_{7}$ in Fig. $1 \mathrm{~b}$ shows the morphology of three-dimensional (3D) hierarchical nano blocks with the jagged edge. The large pore structure between the blocks is beneficial to the storage of electrolyte and gas diffusion. Meanwhile, the "Steps" and "Defects" originating from the jagged morphology (Fig. S2) could offer more exposed active sites and increase the contact area between the catalyst and electrolyte [22]. Magnified high-resolution transmission electron microscopy (HRTEM) image in Fig. 1d corresponds to the region in Fig. 1c that marked with yellow box. The clear lattice spacing of $0.31 \mathrm{~nm}$ is assigned to the (202) plane of orthorhombic $\mathrm{Pr}_{3} \mathrm{IrO}_{7}$. The corresponding selected area electron diffraction (SAED) pattern further confirms the prepared $\mathrm{Pr}_{3} \mathrm{IrO}_{7}$ is single crystal with a $\mathrm{Cmcm}$ space group. As displayed in Fig. If, the atomic resolution high-angle annular dark field- scanning TEM (HAADF-STEM) image displays a periodic light and dark contrast arrangement. As reported, the atomic number determines the brightness of an atom column in an HAADF-STEM image [23]; thus the brightness level of atoms is $\operatorname{Ir}(77)>\operatorname{Pr}(59)$. Energy dispersive spectroscopy (EDS) mapping (Fig. $1 \mathrm{~g}-\mathrm{j}$ ) reveals the even distribution of $\mathrm{O}, \mathrm{Ir}$, and Pr elements throughout the entire catalyst.

The evolution of structure, composition, and valence states on the surface of $\mathrm{Pr}_{3} \mathrm{IrO}_{7}$ under working conditions were investigated using ex situ characterization techniques, including HRTEM, X-ray photoelectron spectroscopy (XPS), X-ray absorption near edge structure (XANES) spectroscopy, and extended X-ray absorption fine-structure (EXAFS) spectroscopy. XPS survey spectrum of the prepared catalysts is shown in Fig. S3, demonstrating the fundamental components of Ir, Pr and $\mathrm{O}$. The binding energies (BEs) of $\mathrm{Ir} 4 \mathrm{f}, \mathrm{Pr} 3 \mathrm{~d}$ and $\mathrm{O} 1 \mathrm{~s}$ for $\mathrm{Pr}_{3} \mathrm{IrO}_{7}$ and $\mathrm{IrO}_{x} / \mathrm{Pr}_{3} \mathrm{IrO}_{7}$ were measured to detect the changes in chemical environment and electronic state of $\mathrm{Ir}$ and $\mathrm{O}$ in the structures. As illustrated in Fig. 2a, two sets of doublet peaks in the Ir $4 \mathrm{f}$ spectra of $\mathrm{Pr}_{3} \mathrm{IrO}_{7}$ and $\mathrm{IrO}_{x} / \mathrm{Pr}_{3} \mathrm{IrO}_{7}$ were fitted. For the $\mathrm{Pr}_{3} \mathrm{IrO}_{7}$ doublet, the peaks with BEs of 62.6 and $65.8 \mathrm{eV}$ are assigned to $\operatorname{Ir} 4 \mathrm{f}_{7 / 2}$ and $\operatorname{Ir} 4 \mathrm{f}_{5 / 2}$, and the adjacent peaks with BEs of 64.1 and $68.7 \mathrm{eV}$ correspond to their shake-up satellites [24]. High oxidation state of $\mathrm{Ir}^{5+}$ in pristine $\mathrm{Pr}_{3} \mathrm{IrO}_{7}$ makes the $\mathrm{BEs}$ of Ir $4 \mathrm{f}$ higher than those of commercial $\mathrm{IrO}_{2}$, which is similar to $\mathrm{Ba}_{2} \mathrm{PrIrO}_{6}\left(\mathrm{Ir}^{5+}\right)$ reported by Cherevko and 

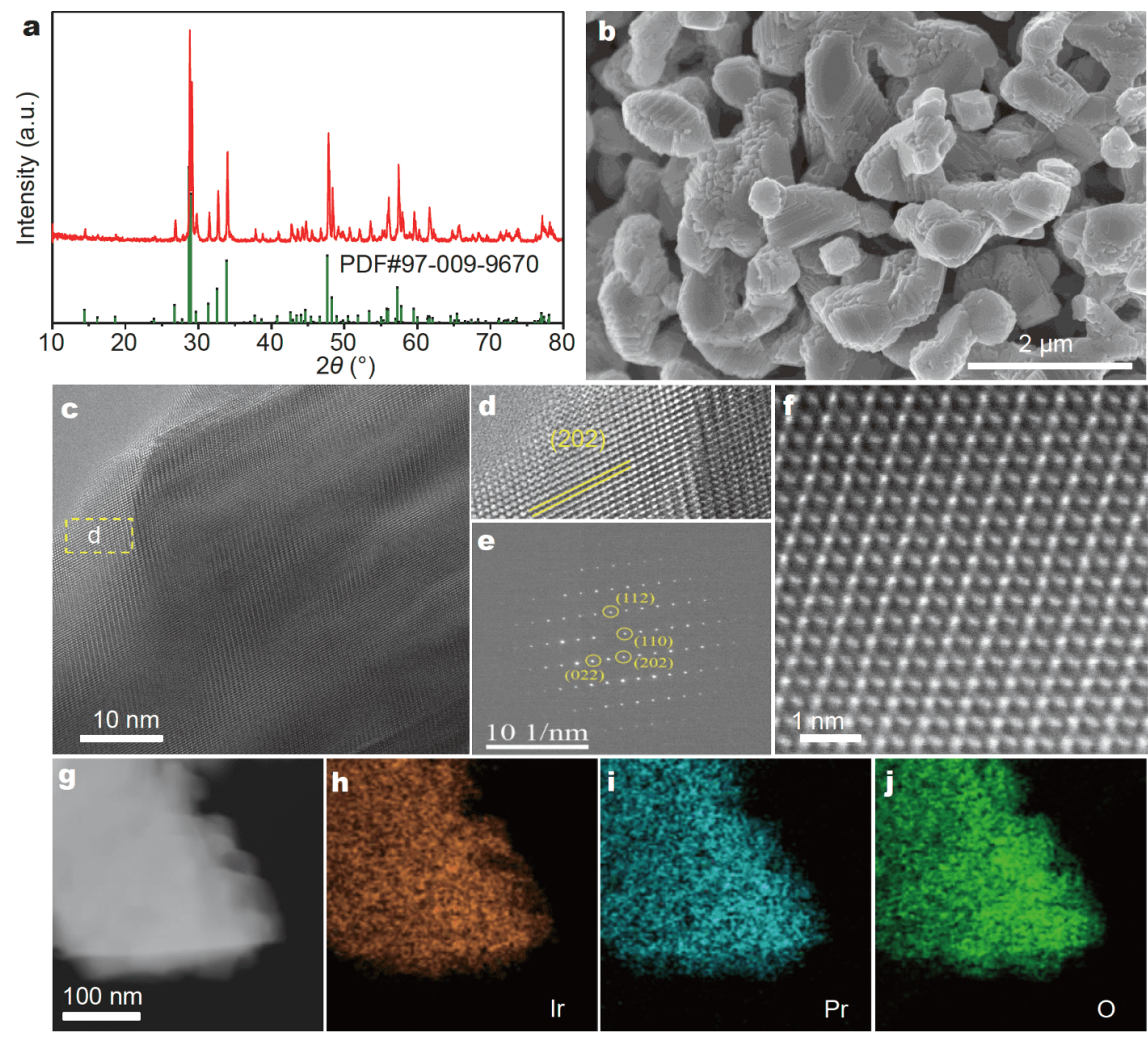

Figure 1 Characterization of the fluorite-type $\mathrm{Pr}_{3} \mathrm{IrO}_{7}$. (a) XRD pattern; (b) SEM image; (c) HRTEM image; (d) magnified HRTEM image; (e) SAED pattern; (f) atomic-resolution HAADF-STEM image; (g-j) EDS elemental mappings of Ir, Pr and O.

coworkers [19]. The doublet of $\mathrm{IrO}_{x} / \mathrm{Pr}_{3} \mathrm{IrO}_{7}$ peaks with BEs of 62.3 and $65.5 \mathrm{eV}$ are related to Ir $4 \mathrm{f}_{7 / 2}$ and $\operatorname{Ir} 4 \mathrm{f}_{5 / 2}$, and the peaks with BEs of 63.8 and $68.0 \mathrm{eV}$ are their shake-up satellites. After OER testing, the doublet peaks for Ir $4 \mathrm{f}_{7 / 2}$ and Ir $4 \mathrm{f}_{5 / 2}$ of $\operatorname{IrO}_{x} / \mathrm{Pr}_{3} \mathrm{IrO}_{7}$ shift to lower energy compared with that of $\mathrm{Pr}_{3} \mathrm{IrO}_{7}$, which is caused by the formation of $\mathrm{IrO}_{x}$, instead of $\mathrm{IrO}_{2}$. As we know, the peak with $\mathrm{BE}$ of $\operatorname{Ir} 4 \mathrm{f}_{7 / 2}$ for $\mathrm{IrO}_{2}$ is usually less than $62.0 \mathrm{eV}$ [25]. Meanwhile, the peaks related to $\operatorname{Pr} 3 \mathrm{~d}_{5 / 2}$ and $\operatorname{Pr} 3 \mathrm{~d}_{3 / 2}$ are both shifted by $0.2 \mathrm{eV}$ toward high binding energies, which may be attributed to the slight oxidation of $\mathrm{Pr}^{3+}$ during the oxygen evolution (Fig. 2b) [26]. Deconvolution of the $\mathrm{O} 1 \mathrm{~s}$ spectrum affords signal of $\mathrm{Ir}-\mathrm{OH}$ in $\mathrm{Pr}_{3} \mathrm{IrO}_{7}$, which appears at $\mathrm{BE}$ of $531.1 \mathrm{eV}$ (Fig. S4) [27]. A weak peak positioned at $532.4 \mathrm{eV}$ is related to oxygencontaining adventitious carbon species, and the peak at $529.2 \mathrm{eV}$ is assigned to the lattice oxygen bound to the $\mathrm{Pr}$ ion in $\mathrm{Pr}_{3} \mathrm{IrO}_{7}$ [13], which shows an obvious decrease in proportion from $53.1 \%$ to $16.7 \%$, along with extensive leaching of surface Pr during electrochemical process (Fig. S4). This behavior is similar to that observed after leaching of $\mathrm{Pr}$ in $\mathrm{Ba}_{2} \mathrm{PrIrO}_{6}$ [19], $\mathrm{Ni}$ in Ir-Ni oxide [28], and $\mathrm{Co}$ in IrCo nanodendrites [29]. After the OER test, the O 1s XPS spectrum of $\operatorname{IrO}_{x} / \mathrm{Pr}_{3} \mathrm{IrO}_{7}$ displays one small peak assigned to oxygen from adventitious $\mathrm{H}_{2} \mathrm{O}$ and carbon species at high $\mathrm{BE}$ of $535.1 \mathrm{eV}$ [27], as well as a broad main peak with a $\mathrm{BE}$ of $531.8 \mathrm{eV}$ assigned to $\mathrm{IrOH}$, which contains much higher $\mathrm{OH}$ content $(67.7 \%)$ than that of $\mathrm{Pr}_{3} \mathrm{IrO}_{7}$ (39.6\%), indicating more Ir catalytic active sites in $\mathrm{IrO}_{x} / \mathrm{Pr}_{3} \mathrm{IrO}_{7}$ compared with $\mathrm{Pr}_{3} \mathrm{IrO}_{7}$.

Fig. $2 c$ shows the Ir $\mathrm{L}_{\mathrm{III}}$-edge XANES spectrum of $\mathrm{IrO}_{x} l$ $\mathrm{Pr}_{3} \mathrm{IrO}_{7}$ compared with the pristine $\mathrm{Pr}_{3} \mathrm{IrO}_{7}$, commercial Ir foil, $\mathrm{IrO}_{2}$, and $\mathrm{IrCl}_{3}$ measured under the same conditions. The white line peak position of $\mathrm{Pr}_{3} \mathrm{IrO}_{7}$ is located at $11,221.0 \mathrm{eV}$, which is shifted to higher energy than the absorption peak of $\mathrm{IrO}_{2}$, indicating a higher Ir oxidation state than that of $\mathrm{IrO}_{2}[16,25]$. While the white line peak position of $\mathrm{IrO}_{x} / \mathrm{Pr}_{3} \mathrm{IrO}_{7}$ exhibits a clear shift toward lower photon energy compared with $\mathrm{Pr}_{3} \mathrm{IrO}_{7}$, which is almost same as that of $\mathrm{IrO}_{2}$, implying the oxidation state of Ir on the surface is closer to +4 . This trend in the change of Ir oxidation state is consistent with the XPS results. The corresponding Fourier transform of EXAFS oscillations gives further insight into the oxidation state of $\mathrm{Ir}$ on the surface of $\mathrm{Pr}_{3} \mathrm{IrO}_{7}$ and $\mathrm{IrO}_{x} / \mathrm{Pr}_{3} \mathrm{IrO}_{7}$ using the Ir-O bond distances as a descriptor [30,31]. In Fig. 2d, 

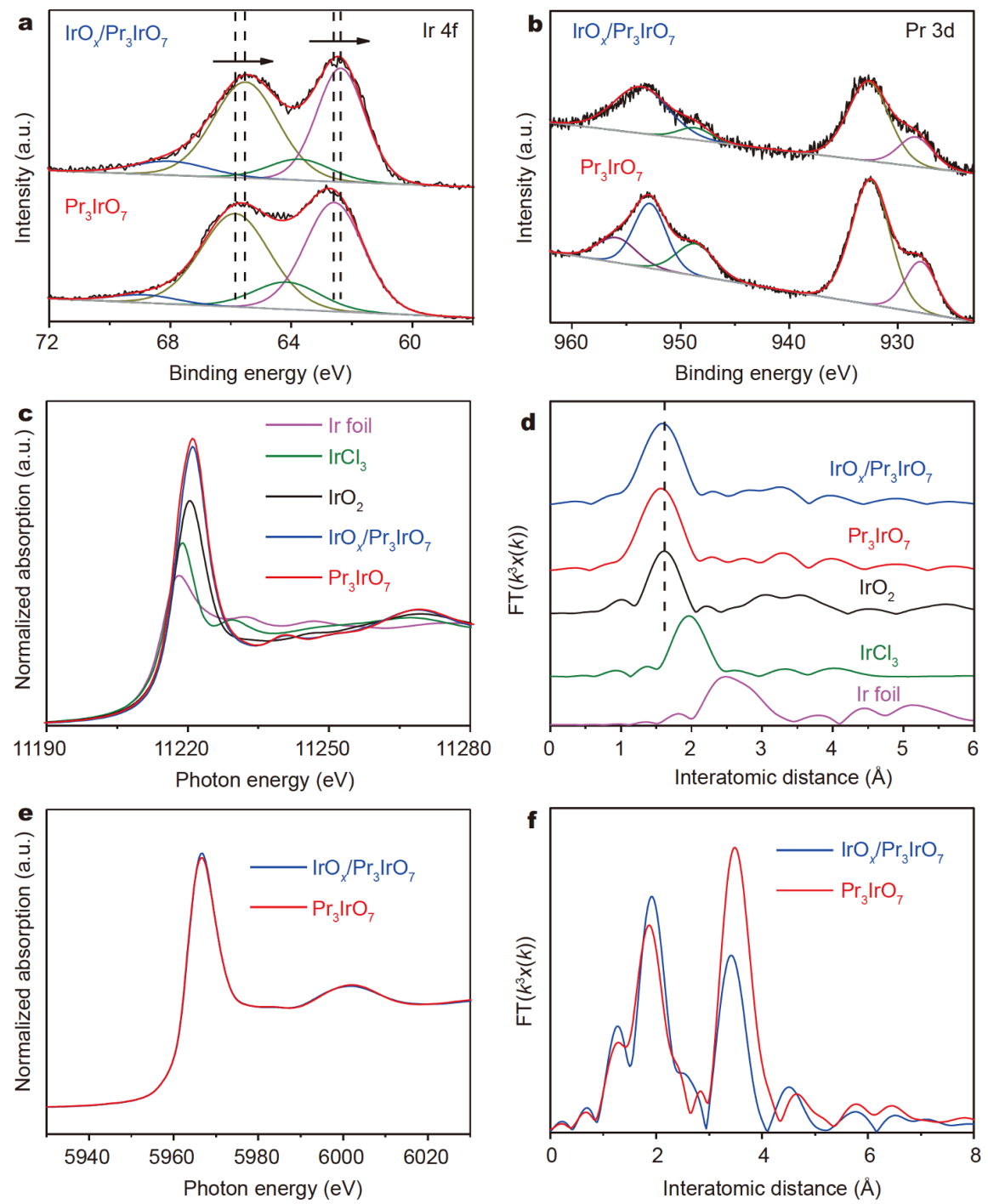

Figure 2 High-resolution XPS spectra of $\mathrm{Pr}_{3} \mathrm{IrO}_{7}$ and $\mathrm{IrO}_{x} / \mathrm{Pr}_{3} \mathrm{IrO}_{7}$. (a) Ir 4f, (b) Pr 3d. (c) $\mathrm{Ir} \mathrm{L}_{\mathrm{III}}$-edge XANES spectra and (d) the corresponding $k^{3}$ weighted Fourier transforms of Ir $\mathrm{L}_{\mathrm{III}}$-edge EXAFS spectra for $\mathrm{Pr}_{3} \mathrm{IrO}_{7}, \mathrm{IrO}_{x} / \mathrm{Pr}_{3} \mathrm{IrO}_{7}$, and references Ir foil, $\mathrm{IrCl}_{3}, \operatorname{IrO}{ }_{2}$. (e) $\operatorname{Pr} \mathrm{L}_{\mathrm{III}}$-edge XANES spectra and (f) the corresponding $k^{3}$-weighted Fourier transforms of $\mathrm{Pr} \mathrm{L}_{\mathrm{III}}$-edge EXAFS spectra for $\mathrm{Pr}_{3} \mathrm{IrO}_{7}$, and $\mathrm{IrO}_{x} / \mathrm{Pr}_{3} \mathrm{IrO}_{7}$.

the main peak of $\mathrm{Pr}_{3} \mathrm{IrO}_{7}$ at $1.57 \AA$ belongs to the $\mathrm{Ir}-\mathrm{O}$ bond derived from electron backscattering of the octahedral $\mathrm{O}$ environment around the central Ir ion. The shorter Ir-O bond in $\mathrm{Pr}_{3} \mathrm{IrO}_{7}$ than that of commercial $\mathrm{IrO}_{2}(1.61 \AA)$ convincingly confirms an oxidation state of Ir that is higher than +4 . For $\operatorname{IrO}_{x} / \mathrm{Pr}_{3} \mathrm{IrO}_{7}$, the resulting peak related to Ir-O corresponds to a bond length similar to that of $\mathrm{IrO}_{2}$, further confirming an oxidation state of approximately +4 . The reduced oxidation state of Ir may be attributed to the loss of oxygen on the surface according to the equation [12]:

$\operatorname{Ir}^{n+} \mathrm{O}_{x} \rightarrow \operatorname{Ir}^{(n-2 \delta)+} \mathrm{O}_{x-\delta}+\frac{\delta}{2} \mathrm{O}_{2(g)}+2 \delta \mathrm{e}^{-}$.
The Pr $\mathrm{L}_{\mathrm{III}}$-edge XANES and EXAFS spectra of $\mathrm{Pr}_{3} \mathrm{IrO}_{7}$ and $\mathrm{IrO}_{x} / \mathrm{Pr}_{3} \mathrm{IrO}_{7}$ can be found in Fig. $2 \mathrm{e}$ and $\mathrm{f}$. For $\mathrm{Pr}_{3} \mathrm{IrO}_{7}$, the XANES spectrum is characterized by strong white line, and the peak position locates at $5966.6 \mathrm{eV}$, much close to that of the trivalent $\operatorname{Pr}$ [32]. After OER testing, the white line of $\mathrm{IrO}_{x} / \mathrm{Pr}_{3} \mathrm{IrO}_{7}$ shows a slight change. Correspondingly, the Fourier transform $\mathrm{Pr} \mathrm{L}_{\mathrm{III}}{ }^{-}$ edge EXAFS spectrum of $\mathrm{Pr}_{3} \mathrm{IrO}_{7}$ shows two main peaks at 1.86 and $3.48 \AA$, respectively. Compared with $\mathrm{Pr}_{3} \mathrm{IrO}_{7}$, the peak positions and intensity of $\mathrm{IrO}_{x} / \mathrm{Pr}_{3} \mathrm{IrO}_{7}$ change obviously, which locate at 1.92 and $3.42 \AA$, respectively.

After electrochemical pre-treatment for 100 cyclic voltammetry (CV) cycles, the OER activity of the $\mathrm{IrO}_{x} /$ 
$\mathrm{Pr}_{3} \mathrm{IrO}_{7}$ catalyst was evaluated in acidic media with scanning potentials from 1.20 to $1.65 \mathrm{~V}$ ( $v s$. RHE) using a standard three-electrode configuration. As a reference, the activity of commercial $\mathrm{IrO}_{2}$ toward the OER was also investigated under the same conditions. The polarization curve of $\mathrm{IrO}_{x} / \mathrm{Pr}_{3} \mathrm{IrO}_{7}$ produces an extremely small onset potential of $1.45 \mathrm{~V}$ ( $v s$. RHE), beyond which the anodic current rises sharply (Fig. 3a). A relatively low overpotential of $305 \mathrm{mV}$ was observed for $\mathrm{IrO}_{x} / \mathrm{Pr}_{3} \mathrm{IrO}_{7}$ at the current density of $10 \mathrm{~mA} \mathrm{~cm}{ }^{-2}$, whereas $\mathrm{IrO}_{2}$ required a higher overpotential $(320 \mathrm{mV})$ to deliver the same current density, indicating higher catalytic activity of $\mathrm{IrO}_{x} / \mathrm{Pr}_{3} \mathrm{IrO}_{7}$. Furthermore, as demonstrated by the Tafel plots (Fig. 3b) derived from linear sweep voltammetry (LSV) (Fig. 3a), Tafel slopes of 37 and $94 \mathrm{mV} \mathrm{dec}{ }^{-1}$ for $\mathrm{IrO}_{x} / \mathrm{Pr}_{3} \mathrm{IrO}_{7}$ and $\mathrm{IrO}_{2}$, respectively, indicate faster kinetics of $\mathrm{IrO}_{x} / \mathrm{Pr}_{3} \mathrm{IrO}_{7}$ for the OER. In addition to high catalytic activity per geometric area, $\mathrm{IrO}_{x} / \mathrm{Pr}_{3} \mathrm{IrO}_{7}$ also delivers outstanding mass activity (normalized by the mass of iridium) (Fig. 3c). The current density $\left(\mathrm{A} \mathrm{g}_{\mathrm{Ir}}{ }^{-1}\right)$ of $\mathrm{IrO}_{x} / \mathrm{Pr}_{3} \mathrm{IrO}_{7}$ is approximately 4.8 times that of $\mathrm{IrO}_{2}$ at $1.58 \mathrm{~V}$ ( $v s$. RHE), further highlighting the superior OER activity of the prepared $\mathrm{IrO}_{x} / \mathrm{Pr}_{3} \mathrm{IrO}_{7}$ catalyst relative to $\mathrm{IrO}_{2}$. We also explored the optimal preparation temperature of $\mathrm{Pr}_{3} \mathrm{IrO}_{7}$ catalysts by varying the annealing temperature from 1000 to $1400^{\circ} \mathrm{C}$. Evidently, the $\mathrm{Pr}_{3} \mathrm{IrO}_{7}$ prepared at $1200^{\circ} \mathrm{C}$ exhibits the highest activity (Fig. S5), the largest electrochemical active surface area (ECSA) determined by $C_{\mathrm{dl}}$ (Fig. 3d, Fig. S6), and the smallest charge transfer resistance $\left(R_{\mathrm{ct}}\right)(120 \Omega)$ (Fig. 3e) among the three catalysts. The OER activities of the catalysts prepared with different molar ratios of Pr to Ir were also evaluated. As confirmed by Fig. S7, the catalyst with the Pr/Ir molar ratio of 2:1 in the reactant shows the highest OER activity. Inductively coupled plasma-atomic emission spectroscopy (ICP-AES) of the electrolyte was applied to detect the amount of dissolved Pr and Ir ions during the OER process, which provides further insight into the changes of structure and composition on the surface of the catalyst. Fig. 3f shows that the initial molar ratio of Pr to Ir in the electrolyte is
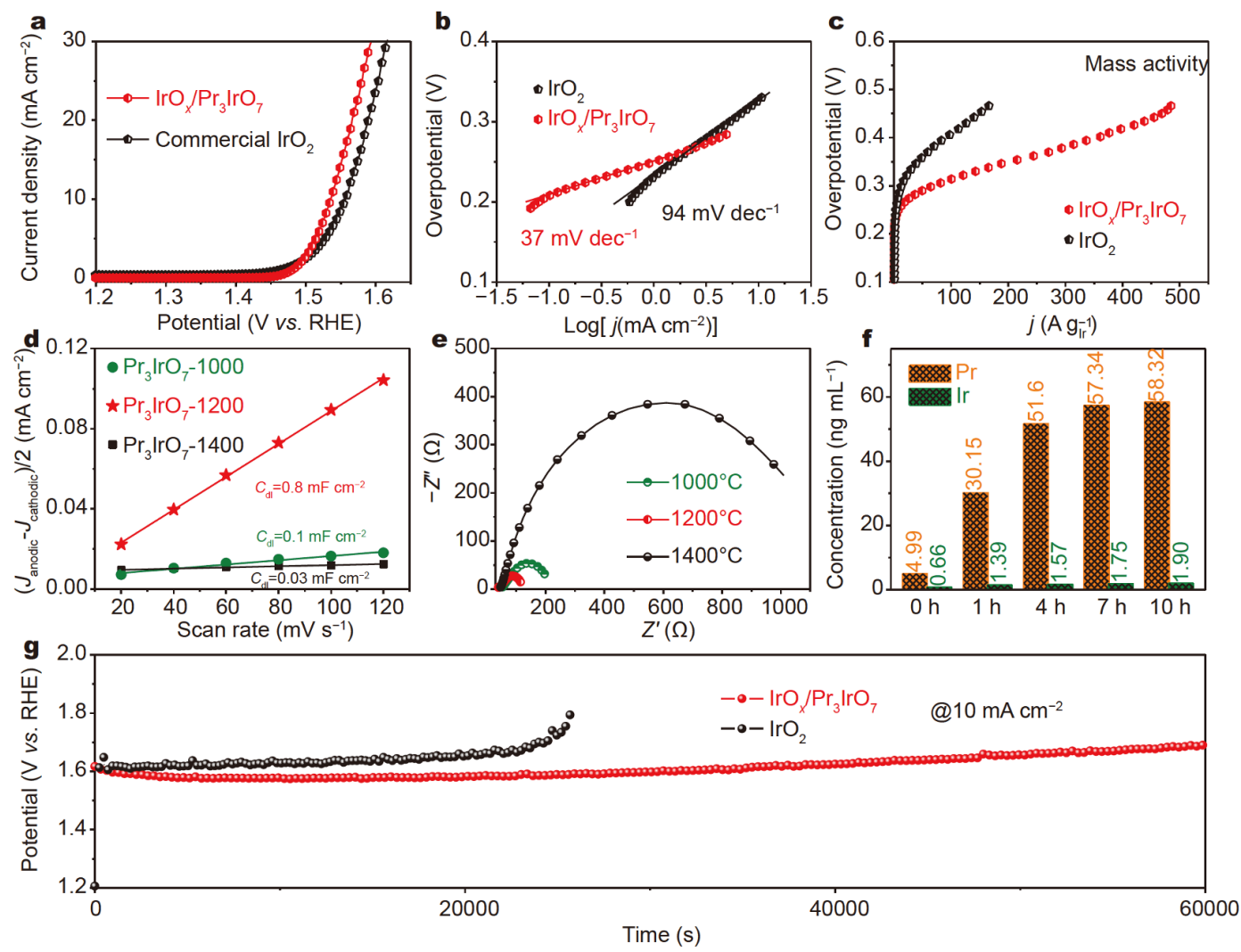

Figure 3 OER performance in $0.1 \mathrm{~mol} \mathrm{~L}^{-1} \mathrm{HClO}_{4}$ medium. (a) Polarization curves of $\mathrm{IrO}_{x} / \mathrm{Pr}_{3} \mathrm{IrO}_{7}$ and commercial IrO $\mathrm{I}_{2}$, (b) Tafel slopes, (c) mass activities (normalized to the mass of $\mathrm{Ir}, \mathrm{A} \mathrm{g} \mathrm{gIr}^{-1}$ ) of $\mathrm{IrO}_{x} / \mathrm{Pr}_{3} \mathrm{IrO}_{7}$ and $\mathrm{IrO}_{2}$. (d) Capacitive currents as a function of the scan rate for $\mathrm{Pr}_{3} \mathrm{IrO}_{7}$ catalysts prepared at different annealing temperatures varied from 1000 to $1400^{\circ} \mathrm{C}$. (e) Nyquist plots for $\operatorname{Pr}_{3} \mathrm{IrO}_{7}$ prepared at $1000,1200,1400^{\circ} \mathrm{C}$, respectively. (f) Time-dependent concentrations of Ir and $\mathrm{Pr}$ in the electrolyte. (g) The durability testing by the chronopotentiometry at a benchmark of $10 \mathrm{~mA} \mathrm{~cm}^{-2}$. 
approximately 7.56 , which is obviously higher than the theoretical ratio in $\mathrm{Pr}_{3} \mathrm{IrO}_{7}$, suggesting that $\mathrm{Pr}$ ions are more easier to be dissolved in the acidic medium under an open circuit than Ir ions. As the OER process proceeds, the molar ratio of Pr to Ir increases to 30:1 after $7 \mathrm{~h}$, demonstrating the more dissolution of $\operatorname{Pr}$ ions into the electrolyte, but from 7 to $10 \mathrm{~h}$, the ratios of $\mathrm{Pr} / \mathrm{Ir}$ dissolution are relatively unchanged. The electrochemical durability of $\mathrm{IrO}_{x} / \mathrm{Pr}_{3} \mathrm{IrO}_{7}$ and $\mathrm{IrO}_{2}$ were also examined via chronopotentiometry at a constant current density of $10 \mathrm{~mA} \mathrm{~cm}^{-2}$ (Fig. 3g). For $\mathrm{IrO}_{x} / \mathrm{Pr}_{3} \mathrm{IrO}_{7}$, the initial potential increases by less than $0.07 \mathrm{~V}$ after continuous OER testing over $60,000 \mathrm{~s}$. In contrast, $\mathrm{IrO}_{2}$ becomes nearly inactive for the OER in less than $20,000 \mathrm{~s}$. The overpotential of $\mathrm{IrO}_{x} / \mathrm{Pr}_{3} \mathrm{IrO}_{7}$ at $10 \mathrm{~mA} \mathrm{~cm}{ }^{-2}$ was then compared with those of recently reported electrocatalysts in acidic media (Table S1), further confirming the competitive performance of $\mathrm{IrO}_{x} / \mathrm{Pr}_{3} \mathrm{IrO}_{7}$.

DFT calculations were performed to explore the energetically preferred catalytic reaction pathway and reveal a possible catalytic reaction mechanism. The structural models and further DFT calculation details are available in the Supplementary information (Figs S8-S10). The adsorbate evolution mechanism (AEM) is classic and universal. Based on previous research, we first assumed that a four-step OER mechanism proceeds as follows: $\mathrm{H}_{2} \mathrm{O} \rightarrow{ }^{\star} \mathrm{OH} \rightarrow{ }^{\star} \mathrm{O} \rightarrow{ }^{\star} \mathrm{OOH} \rightarrow \mathrm{O}_{2}$ (see Equations (S1)(S4) in the Supplementary information) [33]. The Equations (S5)-(S8) in the Supplementary information show the steps of lattice oxygen participation mechanism. As shown in Fig. 4a, c, e, the free energy barrier for $\mathrm{IrO}_{x} /$ $\mathrm{Pr}_{3} \mathrm{IrO}_{7}(002)$ is $2.62 \mathrm{eV}$ to form the ${ }^{\star} \mathrm{OOH}$ at a rate-
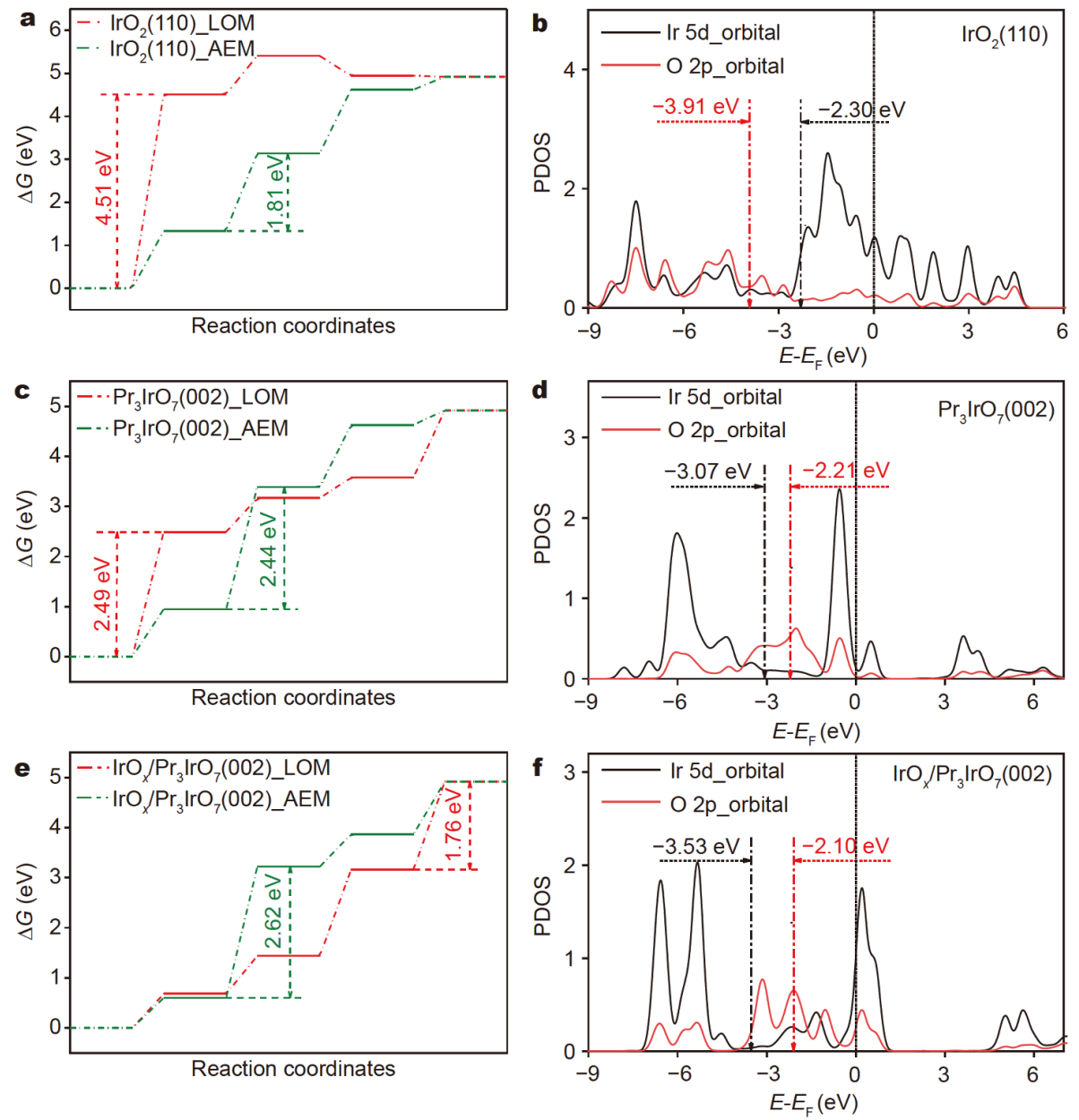

Figure 4 OER free energy diagrams via AEM and LOM, respectively, for (a) $\mathrm{IrO}_{2},(\mathrm{c}) \mathrm{Pr}_{3} \mathrm{IrO}_{7},(\mathrm{e}) \mathrm{IrO}_{x} / \mathrm{Pr}_{3} \mathrm{IrO}_{7}$, in which the corresponding Gibbs free energy differences of the potential-determining step $\left(\Delta G_{\max }\right)$ denoted by dashed arrows. (b), (d), (f) show the PDOS of surface active Ir $5 \mathrm{~d}$ orbitals and $\mathrm{O} 2 \mathrm{p}$ orbitals for $\mathrm{IrO}_{2}, \mathrm{Pr}_{3} \mathrm{IrO}_{7}$ and $\mathrm{IrO}_{x} / \mathrm{Pr}_{3} \mathrm{IrO}_{7}$, respectively. The corresponding band centers of O $2 \mathrm{p}$ and $\mathrm{Ir} 5 \mathrm{~d}$ are denoted by dash lines. 
determining step, which is higher than those of $\mathrm{IrO}_{2}(110)$ and $\mathrm{Pr}_{3} \mathrm{IrO}_{7}(002)$. The free energy barrieres for $\mathrm{IrO}_{2}(110)$ and $\mathrm{Pr}_{3} \mathrm{IrO}_{7}(002)$ of ${ }^{*} \mathrm{OOH}$ formation are 1.81 and $2.44 \mathrm{eV}$, respectively. However, the electrochemical testing results indicate that $\mathrm{IrO}_{x} / \mathrm{Pr}_{3} \mathrm{IrO}_{7}(002)$ shows higher activity than $\mathrm{IrO}_{2}$, suggesting that the $\mathrm{IrO}_{x} / \mathrm{Pr}_{3} \mathrm{IrO}_{7}(002)$ does not follow the AEM, and thus we tried the lattice oxygen mechanism (LOM) with surface Ir atoms as the active sites. The computed results in Fig. 4e show that there is a lower OER barrier of $1.76 \mathrm{eV}$ for $\mathrm{IrO}_{x} / \mathrm{Pr}_{3} \mathrm{IrO}_{7}$ (002) following the LOM, which is much lower than that of 4.51 and $2.49 \mathrm{eV}$ for $\operatorname{IrO}_{2}(110)$ and $\mathrm{Pr}_{3} \mathrm{IrO}_{7}(002)$, respectively. The minimum theoretical overpotential $\left(\eta^{\mathrm{OER}}\right)$ is calculated as $0.53 \mathrm{~V}$ for the $\mathrm{IrO}_{x} / \mathrm{Pr}_{3} \mathrm{IrO}_{7}(002)$ based on LOM mechanism, which is smaller than that of $\operatorname{IrO}_{2}(110)$ $(0.58 \mathrm{~V})$ based on AEM, making the theoretical calculated OER activity of $\mathrm{IrO}_{x} / \mathrm{Pr}_{3} \mathrm{IrO}_{7}(002)$ relative to $\mathrm{IrO}_{2}(110)$ consistent with the experimental data. To better understand the appropriate mechanism to describe $\mathrm{IrO}_{x} /$ $\mathrm{Pr}_{3} \mathrm{IrO}_{7}(002)$, we further explored their surface structures and electronic properties. As shown in Fig. $4 \mathrm{~b}, \mathrm{~d}$, and f, the projected density of states (PDOS) of Ir $5 \mathrm{~d}$ orbitals and $\mathrm{O} 2 \mathrm{p}$ orbitals for surface active Ir ions and lattice oxygen atoms that participate in the OER for $\mathrm{IrO}_{x} /$ $\mathrm{Pr}_{3} \mathrm{IrO}_{7}(002), \mathrm{IrO}_{2}(110)$ and $\mathrm{Pr}_{3} \mathrm{IrO}_{7}(002)$ were calculated. The OER reaction mechanism can be affected by the relative position of oxygen $2 \mathrm{p}$ orbitals and metal $\mathrm{d}$ orbitals $[34,35]$. For $\operatorname{IrO}_{x} / \mathrm{Pr}_{3} \operatorname{IrO}_{7}(002)$, the surface active $\operatorname{Ir} 5 \mathrm{~d}$ orbitals shows a lower energy level than the $2 \mathrm{p}$ orbitals of oxygen that will reduce the charges on oxygen. The charge-reduced oxygen atom will be easy to escape from the lattice to participate the OER process. Thus, it can be concluded that the LOM is a preferred reaction pathway than the AEM for $\mathrm{IrO}_{x} / \mathrm{Pr}_{3} \mathrm{IrO}_{7}(002)$.

\section{CONCLUSIONS}

In summary, we expanded a new member of family for the $\mathrm{IrO}_{x}$-type OER electrocatalyst, which exhibits an enhanced OER activity with a low overpotential of $305 \mathrm{mV}$ compared with that of $\operatorname{IrO}_{2}(320 \mathrm{mV})$ and a better stability. Particularly, the increase of overpotential within $0.07 \mathrm{~V}$ over continuous testing for $60,000 \mathrm{~s}$ at a benchmark of $10 \mathrm{~mA} \mathrm{~cm}^{-2}$ for $\mathrm{IrO}_{x} / \mathrm{Pr}_{3} \mathrm{IrO}_{7}$, in contrast to the inactivation of commercial $\mathrm{IrO}_{2}$ within 20,000 s using glass carbon as the working electrode. The DFT studies reveal that LOM is followed by the $\mathrm{IrO}_{x} / \mathrm{Pr}_{3} \mathrm{IrO}_{7}$ system. Based on the PDOS analysis, the energy level of active Ir $5 \mathrm{~d}$ orbitals is obviously lower than that of ligand $\mathrm{O} 2 \mathrm{p}$ orbitals in $\mathrm{IrO}_{x} / \mathrm{Pr}_{3} \mathrm{IrO}_{7}$, which endows the enough activity of oxygen to participate in the OER process, and thus contributes to the higher OER activity.

Received 17 November 2020; accepted 25 December 2020; published online 17 March 2021

1 Seh ZW, Kibsgaard J, Dickens CF, et al. Combining theory and experiment in electrocatalysis: Insights into materials design. Science, 2017, 355: eaad4998

2 Lettenmeier P, Majchel J, Wang L, et al. Highly active nano-sized iridium catalysts: synthesis and operando spectroscopy in a proton exchange membrane electrolyzer. Chem Sci, 2018, 9: 3570-3579

3 Liu Y, Li X, Zhang Q, et al. A general route to prepare lowruthenium-content bimetallic electrocatalysts for $\mathrm{pH}$-universal hydrogen evolution reaction by using carbon quantum dots. Angew Chem Int Ed, 2020, 59: 1718-1726

4 Song H, Li Y, Shang L, et al. Designed controllable nitrogen-doped carbon-dots-loaded MoP nanoparticles for boosting hydrogen evolution reaction in alkaline medium. Nano Energy, 2020, 72: 104730

5 Li W, Zhao Y, Liu Y, et al. Exploiting Ru-induced lattice strain in CoRu nanoalloys for robust bifunctional hydrogen production. Angew Chem Int Ed, 2020, 60: anie.202013985

6 Song $\mathrm{H}$, Cheng Y, $\mathrm{Li} \mathrm{B}$, et al. Carbon dots and $\mathrm{RuP}_{2}$ nanohybrid as an efficient bifunctional catalyst for electrochemical hydrogen evolution reaction and hydrolysis of ammonia borane. ACS Sustain Chem Eng, 2020, 8: 3995-4002

7 Pi Y, Zhang N, Guo S, et al. Ultrathin laminar Ir superstructure as highly efficient oxygen evolution electrocatalyst in broad $\mathrm{pH}$ range. Nano Lett, 2016, 16: 4424-4430

8 Faustini M, Giraud M, Jones D, et al. Hierarchically structured ultraporous iridium-ased materials: A novel catalyst architecture for proton exchange membrane water electrolyzers. Adv Energy Mater, 2019, 9: 1802136

9 Nong HN, Reier T, Oh HS, et al. A unique oxygen ligand environment facilitates water oxidation in hole-doped $\mathrm{IrNiO}_{x}$ coreshell electrocatalysts. Nat Catal, 2018, 1: 841-851

10 Reier T, Pawolek Z, Cherevko S, et al. Molecular insight in structure and activity of highly efficient, low-Ir Ir-Ni oxide catalysts for electrochemical water splitting (OER). J Am Chem Soc, 2015, 137: 13031-13040

11 Nong $\mathrm{HN}$, Oh HS, Reier T, et al. Oxide-supported $\mathrm{IrNiO}_{x}$ coreshell particles as efficient, cost-effective, and stable catalysts for electrochemical water splitting. Angew Chem Int Ed, 2015, 54: 2975-2979

12 Seitz LC, Dickens CF, Nishio K, et al. A highly active and stable $\mathrm{IrO}_{x} / \mathrm{SrIrO}_{3}$ catalyst for the oxygen evolution reaction. Science, 2016, 353: 1011-1014

13 Diaz-Morales O, Raaijman S, Kortlever R, et al. Iridium-based double perovskites for efficient water oxidation in acid media. Nat Commun, 2016, 7: 12363

14 Sun W, Liu JY, Gong XQ, et al. OER activity manipulated by $\mathrm{IrO}_{6}$ coordination geometry: An insight from pyrochlore iridates. Sci Rep, 2016, 6: 38429

15 Lebedev D, Povia M, Waltar K, et al. Highly active and stable iridium pyrochlores for oxygen evolution reaction. Chem Mater, 2017, 29: 5182-5191

16 Grimaud A, Demortière A, Saubanère $M$, et al. Activation of surface oxygen sites on an iridium-based model catalyst for the oxygen evolution reaction. Nat Energy, 2016, 2: 16189

17 Rong X, Parolin J, Kolpak AM. A fundamental relationship be- 
tween reaction mechanism and stability in metal oxide catalysts for oxygen evolution. ACS Catal, 2016, 6: 1153-1158

18 Binninger $\mathrm{T}$, Mohamed R, Waltar K, et al. Thermodynamic explanation of the universal correlation between oxygen evolution activity and corrosion of oxide catalysts. Sci Rep, 2015, 5: 12167

19 Geiger S, Kasian O, Ledendecker M, et al. The stability number as a metric for electrocatalyst stability benchmarking. Nat Catal, 2018, 1: $508-515$

20 Nishimine $\mathrm{H}$, Doi $\mathrm{Y}$, Hinatsu $\mathrm{Y}$, et al. Phase transition of $\mathrm{Ln}_{3} \mathrm{IrO}_{7}$ $(\mathrm{Ln}=\mathrm{Pr}, \mathrm{Nd}, \mathrm{Sm}, \mathrm{Eu})$ and its low-temperature structure. J Ceram Soc Jpn, 2007, 115: 577-581

21 Severance RC, Fox AH, Mugavero Iii SJ, et al. Synthesis and crystal structures of two polymorphs of trilanthanum iridium septaoxide $\left(\mathrm{La}_{3} \mathrm{IrO}_{7}\right)$. J Chem Crystlogr, 2010, 41: 496-501

22 Wang $\mathrm{C}$, Zheng L, Chang R, et al. Palladium-cobalt nanowires decorated with jagged appearance for efficient methanol electrooxidation. ACS Appl Mater Interfaces, 2018, 10: 29965-29971

23 Yao Y, Gu XK, He D, et al. Engineering the electronic structure of submonolayer $\mathrm{Pt}$ on intermetallic $\mathrm{Pd}_{3} \mathrm{~Pb}$ via charge transfer boosts the hydrogen evolution reaction. J Am Chem Soc, 2019, 141: 19964-19968

24 Ding J, Yang S. Isolation and characterization of $\mathrm{Pr} @ \mathrm{C}_{82}$ and $\mathrm{Pr}_{2} @ \mathrm{C}_{80}$. J Am Chem Soc, 1996, 118: 11254-11257

25 Chen Y, Li H, Wang J, et al. Exceptionally active iridium evolved from a pseudo-cubic perovskite for oxygen evolution in acid. Nat Commun, 2019, 10: 572

26 Fichtner J, Garlyyev B, Watzele S, et al. Top-down synthesis of nanostructured platinum-lanthanide alloy oxygen reduction reaction catalysts: $\mathrm{Pt}{ }_{x} \mathrm{Pr} / \mathrm{C}$ as an example. ACS Appl Mater Interfaces, 2019, 11: 5129-5135

27 Smith RDL, Sporinova B, Fagan RD, et al. Facile photochemical preparation of amorphous iridium oxide films for water oxidation catalysis. Chem Mater, 2014, 26: 1654-1659

28 Spöri C, Briois P, Nong HN, et al. Experimental activity descriptors for iridium-based catalysts for the electrochemical oxygen evolution reaction (OER). ACS Catal, 2019, 9: 6653-6663

29 Meng G, Sun W, Mon AA, et al. Strain regulation to optimize the acidic water oxidation performance of atomic-layer $\mathrm{IrO}_{x}$. $\mathrm{Adv}$ Mater, 2019, 31: 1903616

30 Oh HS, Nong HN, Reier T, et al. Electrochemical catalyst-support effects and their stabilizing role for $\mathrm{IrO}_{x}$ nanoparticle catalysts during the oxygen evolution reaction. J Am Chem Soc, 2016, 138: $12552-12563$

31 Choy JH, Kim DK, Hwang SH, et al. XANES and EXAFS studies on the Ir-O bond covalency in ionic iridium perovskites. J Am Chem Soc, 1995, 117: 8557-8566

32 Lin B N, Lin Y X, Hsu Y Y, et al. Anomalous Pr ordering, Pr $\mathrm{L}_{3^{-}}$ edge and $\mathrm{Cu}$ K-edge XANES studies for the insulating $\mathrm{PrBa}_{2} \mathrm{Cu}_{3}$ $\mathrm{O}_{7-y}$ system. J Low Temperature Phys, 2003, 131: 803-807

33 Miao X, Zhang L, Wu L, et al. Quadruple perovskite ruthenate as a highly efficient catalyst for acidic water oxidation. Nat Commun, 2019, 10: 3809

34 Kuznetsov DA, Naeem MA, Kumar PV, et al. Tailoring lattice oxygen binding in ruthenium pyrochlores to enhance oxygen evolution activity. J Am Chem Soc, 2020, 142: 7883-7888

35 Sun Y, Liao H, Wang J, et al. Covalency competition dominates the water oxidation structure-activity relationship on spinel oxides. Nat Catal, 2020, 3: 554-563

Acknowledgements This work was supported by Taishan Scholar
Program of Shandong Province, China (ts201712045), Shandong Provincial Key Research and Development Program (SPKR\&DP, 2019GGX102069), the Natural Science Foundation of Shandong Province of China (ZR2018BB008), and the Doctoral Found of Qingdao University of Science and Technology (0100229001, 010029081, 010029075).

Author contributions Liu X proposed the research ideas and designed the experiments. Qin Q and Liu X wrote the manuscript and performed the analysis. Wang Y, Liu H, Zhang L, Wei T, and Li H carried out the synthetic, electrochemical experiments and physical characterizations. Liu S carried out the DFT calculations. All the authors participated in this research project.

Conflict of interest The authors declare that they have no conflict of interest.

Supplementary information Materials characterization and supporting data are available in the online version of the paper.

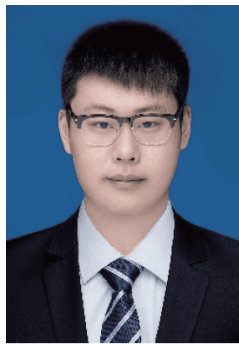

Yimeng Wang is currently studying for his Master degree under the supervision of Prof. Xien Liu at Qingdao University of Science and Technology. At present, his research focuses on the synthesis of metal-doped iridium-based oxide and electrocatalytic oxygen evolution performance in acidic media.

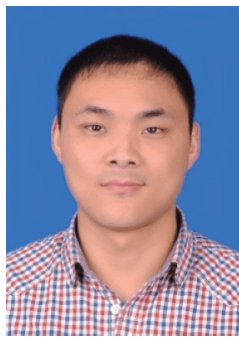

Shangguo Liu received his $\mathrm{PhD}$ degree from Beijing University of Chemical Technology in 2019. And then, He joined the College of Chemical Engineering, Qingdao University of Science and Technology. His research interests focus on exploring chemical and physical properties of materials by theoretical and computational tools.

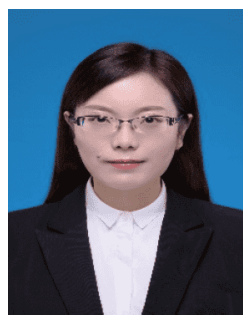

Qing Qin received her PhD degree from Nankai University in 2017. Now she is a professor of Qingdao University of Science and Technology. Her current research interests focus on the design and synthesis of noble metal- and non-noble metal-based electrocatalysts for overall water splitting and $\mathrm{Zn}$-air batteries. 


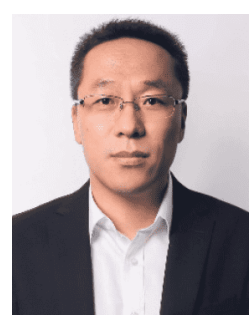

Xien Liu received his $\mathrm{PhD}$ degree from Dalian University of Technology. He is currently a professor of Qingdao University of Science and Technology. His research interests focus on the design of electrocatalysts for electrochemical energy conversion and storage devices.
镨铱氧化物高效催化酸性介质析氧反应

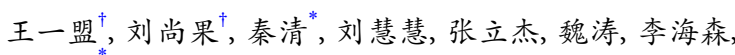
刘希恩 ${ }^{*}$

摘要 非晶态铱氧化物 $\left(\mathrm{IrO}_{x}\right)$ 在酸性介质中具有高的电催化析氧反 应(OER)活性, 但其稳定性不如商业 $\mathrm{IrO}_{2}$. 近年来, 多种非贵金属-铱 混合氧化物展现出高效催化析氧反应的性能. 本文报道了一种含 $\mathrm{IrO}_{x}$ 高活性表面层的立方萤石结构镨铱氧化物 $\left(\mathrm{Pr}_{3} \mathrm{IrO}_{7}\right)$ 催化剂. 该 催化剂在 $0.1 \mathrm{~mol} \mathrm{~L}^{-1} \mathrm{HClO}_{4}$ 溶液中, 表现出高的析氧反应催化活性 和良好的稳定性, 优于商业 $\mathrm{IrO}_{2}$ 和目前报道的大多数催化剂. 在电 流密度为 $10 \mathrm{~mA} \mathrm{~cm}^{-2}$ 时, 该催化剂的过电位为 $305 \mathrm{mV}$, 并具有低的 $\mathrm{Tafel}$ 斜率, 约为 $37 \mathrm{mV} \mathrm{dec}{ }^{-1}$, 表明该催化剂具有更快的反应动力 学. 在持续60000 s的稳定性测试后, 该催化剂的初始电位仅增加了 $0.07 \mathrm{~V}$, 而 $\mathrm{IrO}_{2}$ 只经过 $20000 \mathrm{~s}$ 测试就几乎丧失活性. 密度泛函理论 计算表明, $\mathrm{IrO}_{x} / \mathrm{Pr}_{3} \mathrm{IrO}_{7}$ 催化析氧反应遵循晶格氧机理(LOM). 这项 工作拓展了 $\mathrm{IrO}_{x}$ 型酸性OER电催化剂的种类. 